\title{
Considerações sobre a axiologia donna x femmina para orientar uma tradução brasileira de Boccaccio
}

\author{
Adriana Tulio Baggio \\ Universidade Federal do Paraná \\ atbaggio@gmail.com
}

RESUMO: Delle donne famose, de Donato Albanzani, é um dos vulgarizamentos da coletânea de biografias femininas escrita por Giovanni Boccaccio na década de 1360. Um projeto de tradução desse vulgarizamento levanta a questão sobre a pertinência de se traduzir por "fêmea" o femmina adotado na obra (que se alterna com o uso de donna), já que os sentidos negativos do termo, no italiano do século XIV, eram distintos e menos depreciativos que do que aqueles do correspondente em português. Para examinar tal pertinência, observou-se as ocorrências de donna e femmina no texto do livro com base em três situações: diferenciação por classe de palavras, semantismo dos termos e de seus predicados, e contexto das ocorrências. A análise revela a constituição de axiologias que homologam a oposição natureza x cultura, com femmina em posição disfórica associada à "natureza". Como as acepções depreciativas de "fêmea" se fundam na projeção de aspectos "animalizados" na mulher, pretensamente oriundos de um estágio pré-cultural e humano, o termo pode ser considerado pertinente para traduzir o femmina e evocar os sentidos que ajuda a produzir no texto italiano.

Palavras-chave: Literatura italiana medieval. De mulieribus claris. Axiologia do feminino. Mulher x fêmea. Tradução.

ABSTRACT: Delle donne famose, di Donato Albanzani, è una delle volgarizzazioni della raccolta di biografie femminili scritta da Giovanni Boccaccio negli anni Sessanta del Trecento. Un progetto di traduzione al portoghese brasiliano di questa volgarizzazione mette in rilievo la questione della pertinenza di si tradurre come fêmea la parola "femmina" (adoperata in alternanza alla parola donna), poiché i significati negativi del termine, nellitaliano del XIV secolo, erano distinti e meno denigratori di quelli del corrispondente portoghese. Per esaminare tale pertinenza, si ha osservato le occorrenze delle parole "donna" e "femmina" nel testo del libro sulla base di tre situazioni: la differenziazione per classe di parole, la semantica dei termini e dei loro predicati e il contesto delle occorrenze. L'analisi rivela la costituzione di assiologie che sanciscono l'opposizione natura x cultura, con il termine "femmina" in una posizione disforica associata alla "natura". Poiché i significati dispregiativi di fêmea si basano sulla proiezione di aspetti "animalizzati" nelle donne, presumibilmente da una fase pre-culturale e umana, il termine può essere considerato pertinente per tradurre la parola "femmina" e per evocare i sensi che questa aiuta a produrre nel testo italiano. 
Parole chiave: Letteratura italiana del medioevo. De mulieribus claris. Assiologia del femminile. Donna x femmina. Traduzione.

ABSTRACT: Donato Albanzani's Delle donne famose is one of the Italian translations of the collection of female biographies written by Giovanni Boccaccio in the 1360s. A Brazilian translation project of this work rises the question if it would be pertinent to use the Portuguese word fêmea for the Italian femmina (which appears alternately with donna to referes to women), since the negative meanings of the term, in 14th century Italian, were distinct and less disparaging than those of its Portuguese correspondent. To examine such pertinence, we observe in the text of the book the occurrences of donna and femmina based on three situations: differentiation by class of words, semanticism of terms and their predicates, and context of occurrences. The analysis reveals the constitution of axiologies that ratify the nature $\mathrm{x}$ culture opposition, with femmina in a dysphoric position associated with "nature". As the derogatory meanings of fêmea are based on the projection of "animalized" aspects in women, supposedly from a pre-cultural and human stage, the term can be considered relevant to translate the word femmina and to evoke the senses that it helps to produce in the Italian text.

Keywords: Medieval Italian literature. De mulieribus claris. Axiology of the feminine. Woman x female. Translation.

\section{Introdução}

De mulieribus claris é uma coletânea de 106 biografias de mulheres escrita em latim por Giovanni Boccaccio nos anos $1360^{1}$, traduzida para o vulgar italiano ainda no século XIV. Um desses vulgarizamentos, o de Donato Albanzani $^{2}$, recebeu no século XIX edições organizadas por Luigi Tosti (BOCCACCIO, 1836) e por Giacomo Manzoni (BOCCACCI, 1881, 1882). A tradução ${ }^{3}$ referida no título deste artigo parte do vulgarizamento de Albanzani na edição de Manzoni, intitulada Delle donne famose.

\footnotetext{
${ }^{1} \mathrm{O}$ ano de 1362 como marco da versão definitiva da obra foi consenso durante muito tempo. Estudos mais recentes, como os de Silvia Argurio e Valentina Rovere (2017), sugerem que as fases redacionais podem ter acontecido entre o final dos anos 1350 e o início de 1370.

2 Albanzani teria iniciado o vulgarizamento no final dos anos 1360 e escrito a versão definitiva depois de 1382 e antes de 1388 (TOMMASI, 2020).

${ }^{3}$ Em processo de edição pela Editora da UFPR. Uma tradução parcial da obra (40 capítulos) a partir do texto latino integrou a dissertação de mestrado de Talita Janine Juliani (2011).
} 
Para designar pessoas do sexo feminino, no texto latino, Boccaccio usa os termos femina e mulier, traduzidos no italiano como femmina e donna. Femina (do qual derivam o italiano femmina e o português "fêmea") e mulier (do qual derivam o italiano antigo muliere e o português "mulher") referem-se a fisicalidades percebidas ou atribuídas ao sexo feminino (respectivamente, fertilidade e molícia, esta no sentido de moleza, flexibilidade). Já o italiano donna, assim como o português "dona", vem do latim domina, relacionado a uma posição social da mulher: senhora, proprietária, patroa.

A axiologia no italiano articula, então, um termo relacionado à natureza (femmina) e outro à cultura (donna). No italiano contemporâneo, femmina como designação de pessoa convoca alguns sentidos negativos. No século XIV, o termo também era disfórico em relação a donna, mas não necessariamente ofensivo; femmina poderia indicar o sexo feminino em geral, um conjunto de mulheres ou mulheres de baixo estatuto social (empregadas, populares), enquanto donna designaria uma mulher específica enquanto ser social, ou, então, as senhoras ou as filhas e esposas dos senhores.

Donna já no trecento começou a reunir os semantismos do latim femina e mulier, passando femmina a assumir sentidos decididamente depreciativo, como em algumas obras de Dante Alighieri (DELCORNO, 1970). Um estudo de Mario Bonfante ${ }^{4}$ sobre as ocorrências de donna e femmina na Divina comédia mostra que o primeiro, conotando nobreza e valor, aparece 96 vezes, todas fora do "Inferno"; já o segundo, lembrete da identidade carnal da mulher, aparece nove vezes, nunca no "Paraíso".

À primeira vista esse par pode ser traduzido no português brasileiro (daqui em diante PB) como "mulher" e "fêmea". Mas designar um ser humano como "fêmea" é bastante depreciativo. Será que a axiologia que se estabelece entre os

\footnotetext{
${ }^{4}$ BONFANTE, Mario. Femmina and donna [1956]. In: Studia philologia et litteraria in honorem L. Spitzer. Bern: Francke, 1958. p. 77-109 citado por Victoria Kirkham (1989).
} 
termos no PB recobriria adequadamente aquela que se articula entre os semantismos de donna e femmina no vulgarizamento de Albanzani?

Para responder tal questão analisa-se, neste artigo, a ocorrência dos dois termos no Delle donne famose, buscando verificar se produzem outros efeitos de sentido além daqueles dicionarizados. A análise considera categorias que emergem do próprio texto como pontos de interesse: classe de palavras (donna e femmina ocorrem como nome e como adjetivo, em locuções como di femmina e di donna, "de fêmea" e "de mulher"); semantismo (dos nomes ou dos predicados que acompanham os termos); e contexto ou biografia das ocorrências.

Já adiantando um resultado, conta-se 314 ocorrências para donna e 106 para femmina $a^{5}$ uma relação $75 \%$ x 25\%. Nota-se, portanto, que em Delle donne famose há maior participação de femmina do que a observada por Bonfante na Divina comédia, marca que pode se somar às muitas outras que manifestam a diferença entre as duas obras e entre as ideologias de seus autores.

Feita essa constatação introdutória, passemos às análises dos aspectos indicados.

\section{Diferenciação por classe de palavras: femmina e donna como adjetivo e como nome}

Enquanto classes de palavras, os termos podem ser substantivos ou funcionar como adjetivos, quando compõem as locuções di femmina e di donna e suas variações ${ }^{6}$.

Há mais adjetivos formados com donna (60\%) do que com femmina (40\%), até porque a ocorrência do primeiro termo é maior. No entanto, 16\% dos usos de donna é como adjetivo (e 84\% como substantivo); para femmina, a incidência

\footnotetext{
${ }^{5}$ Inclui-se nessa contagem as palavras femminete e donniciuola, dois diminutivos normalmente usados com sentido depreciativo ("femeazinha", "mulherzinha") e com uma ocorrência cada.

${ }^{6}$ Singular ou plural (femmine, donne), preposição simples ou articulada (di, della, delle).
} 
desse uso é de 32\% (68\% como substantivo). Uma primeira constatação, portanto, é que na formação de locuções adjetivas o termo femmina foi preferido ao donna.

Essas locuções poderiam ser substituídas pelos adjetivos correspondentes, femminile e donnesco; de fato, ambos aparecem no livro, mas em pouquíssimas ocorrências: duas para o primeiro, uma para o segundo. Por algum motivo, o enunciador preferiu a locução adjetiva ao adjetivo.

Se o livro propõe modelos de virtude a serem seguidos e exemplos de má conduta a serem evitados, parece importante entender de que modo são usadas essas locuções e quais nomes elas predicam, na medida em que esse uso manifesta a ideologia que sustenta o contrato moral proposto por Boccaccio (e por Albanzani).

\section{Semantismo dos nomes predicados pelos termos em função adjetiva e dos adjetivos que qualificam os termos em função de substantivo}

As locuções adjetivas qualificam substantivos concretos e abstratos. Alguns aparecem adjetivados apenas como di femmina, outros apenas como di donna, e um terceiro grupo inclui aqueles que aparecem com ambas as locuções.

Os substantivos caracterizados apenas como di femmina são fraqueza, estratagema, coisa, matéria, engano, molícia, arte, avareza/ganância, furor, lascívia, leviandade, malícia, multidão, obra, medo, tumulto, sexo, veneno ${ }^{7}$. Os substantivos caracterizados apenas como di donna são roupa, grupo, cérebro, contenção, costumes, deliberação, defesa, exemplo, feitos, fé, figura, fortuna, o gritar, milícia, natureza, honestidade, honra, opinião, ornamento, palavra, piedade, regulamento, desdém, timidez, hábito, vergonha, virtude ${ }^{8}$.

\footnotetext{
${ }^{7}$ Debolezza, scaltrimento, cosa/matteria, inganno, morbidezza, arte, avarizia, furore, lascivia, leggerezza, malizia, moltitudine, opera, paura, romore, sesso, veleno.

8 Abito, brigata, cerebro, contenzione, costumi, deliberazione, difesa, esempio, fatti, fede, figure, Fortuna, gridare, milizia, natura, onestà, onore, opinione, ornamento, parole, pietà, regola, sdegno, trepidita, usanza, vergogna, virtù.
} 
Quando esses substantivos são organizados em categorias (quadro 1) e se avalia a foria de sua presença no texto, emergem alguns efeitos de sentido.

Quadro 1 - Ocorrência e categorização de substantivos que acompanham as locuções adjetivas di femmina e di donna em Delle donne famose.

\begin{tabular}{|c|c|c|}
\hline & di femmina & di donna \\
\hline Corpo & fraqueza, molícia & \\
\hline Indumentária & & roupa, ornamento \\
\hline Intelecto & estratagema, engano & $\begin{array}{l}\text { cérebro, deliberação, defesa, opinião, } \\
\text { palavra }\end{array}$ \\
\hline $\begin{array}{l}\text { Base para as } \\
\text { atitudes }\end{array}$ & coisa, matéria & costumes, hábito, regulamento \\
\hline Produto das ações & arte, obra & feitos \\
\hline Caráter e paixões & $\begin{array}{l}\text { avareza/ganância, furor, lascívia, } \\
\text { leviandade, malícia, veneno, medo }\end{array}$ & $\begin{array}{l}\text { contenção, honestidade, honra, piedade, } \\
\text { timidez, vergonha, virtude, fé, desdém }\end{array}$ \\
\hline Coletivo & Multidão & grupo, milícia \\
\hline Som característico & Tumulto & o gritar \\
\hline Essência & Sexo & natureza \\
\hline Modelo & & exemplo, figura \\
\hline Destino & & fortuna \\
\hline $\begin{array}{l}\text { Nomes adjetivados } \\
\text { pelas duas locuções }\end{array}$ & \multicolumn{2}{|c|}{ astúcia, coração, exercício/trabalho, modo } \\
\hline
\end{tabular}

Fonte: elaborado por [autor] a partir de Boccacci (1881, 1882) e Boccaccio (1545)

Nomes que se referem a características corporais são adjetivados apenas com locuções formadas por di femmina; no contexto do livro, essas características são disfóricas em oposição àquelas associadas ao masculino (força, rigidez, coragem); quando esse corpo é vestido, a composição do adjetivo é feita com donna. 
Em termos de ações do intelecto, predicados com femmina têm a ver com dissimulação, esperteza; com donna, trata-se de raciocínio, deliberação, argumentação, defesa pública por meio da palavra. Femmina tem coisas e matéria na base de suas atitudes; donna tem costumes, hábitos, regras; femmina tem artes e obras como produtos de suas ações, e donna, feitos.

Um coletivo de mulheres é multidão se for di femmina e grupo ou milícia se for di donna; aquela é menos diferenciada e é amorfa; nestes há particularização e organização. A respeito de uma pretensa ontologia feminina, sexo é di femmina e natureza é di donna. Simulacros femininos - o que sugerem os substantivos exemplo e figura — são apenas di donna, assim como o destino (fortuna).

Quanto a aspectos de caráter e das paixões que movem ou afetam as mulheres, há uma grande diferença nos nomes adjetivados com di femmina e aqueles com di donna. Os primeiros são majoritariamente disfóricos; os segundos, eufóricos.

Há então o terceiro grupo: os substantivos que aparecem predicados com as duas formas locucionárias: astúcia, coração, exercício/trabalho e modo9. Para esses, vale observar também as situações de uso.

Astúcia di donna foi usado para se referir a Penélope e à sua ideia de condicionar o casamento (com um dos pretendentes que a cercavam devido à suposta morte de Ulisses) ao término de um trabalho de tecelagem, que ela desmanchava toda noite. Astúcia di femmina diz respeito ao fato de Semíramis fazer-se passar pelo filho (e ele por ela) para que pudesse governar os assírios. Na axiologia do livro, Penélope é exemplo de virtude e Semíramis de vitupério.

Coração di donna é da biografia da jovem romana que amamenta a própria mãe, presa e condenada a morrer por fome; coração di femmina na biografia de Atália, que mata toda sua família para garantir o trono de Jerusalém. Os dois

\footnotetext{
${ }^{9}$ Cuore, astuzia, esercizio/ lavorio e modo.
} 
usos dizem respeito a uma característica atribuída às mulheres de maneira geral (compaixão, piedade). Também aqui femmina é usado para a personagem condenável, e donna para a louvável.

Exercício ou trabalho di femmina e di donna são aquelas atribuições naturais das mulheres, como pentear os cabelos ou (especialmente) trabalhos como o fiar com a roca. As ocorrências se dividem igualmente entre os dois termos, e a única diferença em relação às biografias é que o exercício di femmina é deixado de lado por atividades físicas, especialmente bélicas (Semíramis, as amazonas Marpésia e Lâmpedo, a virgem Camila que lutou contra Enéas), enquanto o exercício di donna é oposto mais a trabalhos intelectuais (Tamires e Márcia, pintoras) do que corporais (Zenóbia).

Por modo di femmina ou di donna se entende a maneira típica das mulheres de fazer as coisas. O substantivo ocorre mais vezes com a primeira locução (cinco) do que com a segunda (duas). Quase sempre ele é acompanhado de uma negação (non al modo di femmina/ di donna), para descrever modos que as mulheres não seguiram, preferindo o modo dos homens. De fato, esse é o mais frequente recurso retórico usado por Boccaccio para elogiar as mulheres: dizer que elas se comportaram como homens ${ }^{10}$.

Os modos que elas recusaram foram: chorar pela morte do filho (Tômiris), dobrar-se diante da morte iminente (Mariane), ser magnífica de modo feminino (rainha Joana), montar a cavalo de modo feminino (Pentesileia), escrever versos de modo feminino (Semprônia). Essas duas últimas ações, usadas com modo di donna, são em si atribuídas mais naturalmente aos homens.

As duas ocorrências sem negação — ou seja, quando a locução descreve alguma coisa que efetivamente realizada ao modo "de mulher" — têm a ver com travestimento, prática condenada na ideologia boccacciana. As mulheres dos

\footnotetext{
${ }^{10}$ O recurso retórico também está na Divina comédia, segundo a análise de Victoria Kirkham (1989, p. 32), que observa a androginia de Beatriz como fator que aumenta seu poder e aprimora o seu ser. $\mathrm{Na}$ condição de uma mulher-homem, ela exemplificaria o ideal da conjunção de opostos.
} 
companheiros de Jasão vestem os maridos ao modo di femmina para ajudá-los a escapar da prisão, e Hércules se senta ao modo di femmina, vestido de mulher, fiando com a roca junto às femminete.

Ao ocorrerem como substantivo, os termos femmina e donna podem vir ou não acompanhados de adjetivos. A língua italiana classifica os adjetivos (PANEBIANCO; PISONI; REGGIANI, 2017, p. 87) em qualificativos, que expressam uma qualidade do nome (donna nobile, "mulher nobre"), e determinativos, que especificam aspectos como pertencimento (pronomes possessivos — loro donne, "as mulheres deles"), identidade e posição (pronomes demonstrativos — questa donna, "esta mulher"), quantidade (numerais — due donne, "duas mulheres") entre outros.

No contexto deste trabalho, a análise da ocorrência dos termos como substantivo é dividida em dois grupos: o grupo dos nomes acompanhados por adjetivos qualificativos e o grupo dos nomes sem acompanhamento de adjetivo ou acompanhados de adjetivo determinativo. Iniciemos por este segundo, que é menos numeroso.

Algumas ocorrências desse grupo incluem variações dos nomes donna e femmina que sugerem outras acepções além de "pessoa do sexo feminino". Para femmina, essas ocorrências são femminete, o sintagma com pronome possessivo le sue femmine e a locução femmina di popolo. Para donna, elas são donniciuola, donna di popolo e os sintagmas tua donna, donna dei (tedeschi, por exemplo).

Femminete ("femeazinhas") é depreciativo não só pela indicação do dicionário mas também porque designa as moças com quem um afeminado Hércules se senta para fiar, vestido de mulher, no já mencionado episódio da biografia de Íole. Femmina acompanhado de pronome possessivo (le sue femmine, "as suas fêmeas") indica as mulheres da casa. São as mulheres da corte de Semíramis, do harém de Sapor (rei persa derrotado por Zenóbia) e as acompanhantes de Lucrécia. Em femmina di popolo ("fêmea do povo") a locução 
adjetiva é qualificativa, mas mais do que qualificar ela faz referência à mulher de um grupo social específico que é a plebe, no contexto da biografia da romana Megúlia Dotata.

Donniciuola ("mulherzinha"), depreciativo, é usado para se referir a Júlia Soêmia, mãe do imperador Heliogábalo, indigna de ser recebida no senado romano $^{11}$. Donna di popolo tem sentido de plebeia assim como femmina di popolo. Essa versão aparece da biografia da romana Virgínia, que construiu um templo para ser frequentado pelas mulheres expulsas do templo das mulheres dos patrícios (classe superior na sociedade da república romana).

Há uma diferença de valoração entre os contextos dos usos de femmina di popolo e donna di popolo, ainda que ambos signifiquem a mulher plebeia. $\mathrm{Na}$ biografia de Megúlia, critica-se a ambição e a ostentação dos dotes de casamento, exigências feitas até pelas mulheres do povo (ou seja, mulheres que, em teoria, não deveriam aspirar ou demandar joias e dotes preciosos); na de Virgínia, as mulheres do povo são honradas por buscarem construir um templo onde possam cumprir os rituais de castidade exigidos das romanas honestas (ou seja, é uma valorização dos rituais patrícios pela plebe). Enquanto o enunciador critica aquelas, louva estas.

Uma das ocorrências do nome donna acompanhado de pronome possessivo está na biografia de Vetúria, quando diz "tua mulher" ao filho Cneu Márcio, referindo-se à nora. Com o complemento de propriedade (donne dei, "mulheres dos"), aparece no caso das mulheres dos companheiros de Jasão, das mulheres dos flamengos e tedescos, das mulheres dos patrícios. Muitas dessas ocorrências têm a mulher com o sentido de cônjuge, ainda que o texto também use (mais frequentemente) o termo moglie ("esposa") para designar esse papel.

\footnotetext{
11 "Não vês uma mulherzinha cheia de infâmia macular os postos dos Curiões, dos Fabrícios, dos Cipiões e Catões?" (BOCCACCIO, 1545, p. 130S). Tradução nossa para: "Non vedi una donniciuola piena d'infamia bruttare i luoghi d'i Curioni, d'i Fabricii, d'i Scipioni e Catoni?". A fonte aqui é o vulgarizamento de Giuseppe Betussi, do século XVI, pois Albanzani excluiu de seu projeto a biografia de Júlia Soêmia por considerá-la muito licenciosa. $\mathrm{Na}$ tradução da obra ao $\mathrm{PB}$, essa biografia é reincorporada, vertida a partir de Betussi.
} 
Outras se referem às mulheres de uma família ou grupo étnico, e então podem incluir filhas e outras parentes.

Diferentemente do que acontece com o mesmo tipo de locução com o termo femmina, em todas as ocorrências de donna com pronome possessivo, há vínculo familiar patriarcal e sancionado positivamente. Mulheres (Semíramis, Lucrécia) são "proprietárias" de femmine, normalmente servas e empregadas; homens são "proprietários" de donne. Sapor tem femmine, mas se trata de um harém, daí a possível escolha do termo. Esse tipo de relação se estabelece em culturas (africanas e asiáticas) frequentemente desaprovadas pelo enunciador no decorrer do texto.

Há, por fim, um outro uso para donna que significa não apenas mulher, mas "senhora". É a acepção que corresponde ao "dona" do português, um título. Esse uso aparece em Eva, "imortal senhora de todas as coisas"; em Cleópatra e em Flora, quando Boccaccio se refere a Roma como "senhora do mundo"; ainda em Flora, feita senhora dos prados de flores por Zéfiro; e na biografia de Joana, rainha a quem Boccaccio almejava agradar com a obra, dita "senhora e rainha".

Tratemos agora do outro grupo das ocorrências de femmina e donna, aquele em que os substantivos são acompanhados por adjetivos qualificativos. Para o nome femmina, observa-se em 30\% das ocorrências o acompanhamento de adjetivo qualificativo; para o nome donna, esse índice é de 44\%. Donna, portanto, é a opção mais usada na qualificação (e não apenas na indicação dêitica ou na informação sobre "pertencimento") das mulheres como indivíduos.

Adjetivos qualificativos podem vir antes ou depois do nome, e essa diferença de posição origina uma subclassificação. Não sempre, mas normalmente — explicam as gramáticas (PANEBIANCO; PISONI; REGGIANI, 2017, p. 88) — quando precede o nome o adjetivo qualificativo tem função descritiva (disonesta femmina), e quando segue o nome tem função 
restritiva ou distintiva (femmina disonesta). O primeiro caso dá mais ênfase ao nome, o segundo ao adjetivo; o primeiro descreve uma mulher, o segundo inclui a mulher em uma categoria, um tipo.

Pelos exemplos dados entre parêntesis, nota-se que o enunciador do Delle donne famose alterna as duas posições no uso do adjetivo. Pode-se colher alguma informação sobre a diferença desses modos de colocação?

Tanto em femmina quanto em donna, a maior parte dos adjetivos que acompanham os nomes vem antes deles, ou seja, a função descritiva é mais presente do que a restritiva. Essa segunda função aparece especialmente para designar a origem das mulheres (romana, grega, da Ásia, de Chipre), seu estatuto social (casada, liberta) ou religioso (cristã). Ou seja, seu uso ressalta a distinção entre essas mulheres e outras no enquadramento dessas categorias (origem, estatuto social, religião).

Os adjetivos gentílicos aparecem exclusivamente com o termo donna. A distinção religiosa também ocorre apenas com donna, mas há uma variação significativa quanto à colocação do adjetivo a depender da "categoria" religiosa: donna cristiana (adjetivo restringe e distingue, ênfase no "cristã") e pagana donna (função descritiva, ênfase em "mulher"). Os adjetivos que representam estatuto social aparecem uma vez acompanhando femmina e em outra acompanhando donna. A femmina é libertina ("fêmea liberta": ex-escrava, filha de escravos) e a donna é maritata ("mulher casada").

Já foi dito que a maior parte dos adjetivos é descritiva, ou seja, precede o nome. Como a análise desse grupo tomará mais tempo, tratemos antes de um outro subconjunto: o dos adjetivos que ocorrem, para os dois termos, nas duas posições.

O primeiro caso é o já mencionado disonesta femmina/femmina disonesta. Há duas ocorrências com o adjetivo preposto (disonesta femmina), uma na biografia 
de Lena ${ }^{12}$ e outra na biografia de Vênus ${ }^{13}$, descrevendo as personagens. Com o adjetivo posposto ao nome, a ocorrência também é em Vênus ${ }^{14}$, e serve para classificar a biografada como um certo tipo de mulher. E, de fato, na ideologia boccacciana Vênus não só está entre as desonestas como simboliza esse tipo de mulher e a pior das desonestidades femininas.

Com donna, a alternância de posição do adjetivo ocorre mais vezes (quadro 2); especialmente significativos são os casos que destoam do "normal" para aquele adjetivo (ocorrem menos numa posição do que em outra), como "nobre", "romana" e "famosa".

Quadro 2 - Ocorrência de adjetivos qualificativos em posição anterior e posterior ao nome donna e sua distribuição em biografias do Delle donne famose.

\begin{tabular}{|l|l|l|}
\hline & \multicolumn{1}{|c|}{ descritivo/anterior } & \multicolumn{1}{c|}{ restritivo/posterior } \\
\hline Digna & Hipsicratea & Proba \\
\hline Famosa & Várias & Camiola; título \\
\hline Forasteira & Epícaris & Latona \\
\hline Gloriosa & Emília; Sulpícia & Artemísia \\
\hline Nobre & Várias & Vetúria; Teoxena \\
\hline Romana & Vetúria; Paulina & Várias \\
\hline
\end{tabular}

Fonte: elaborado por [autor] a partir de Boccacci (1881, 1882) e Boccaccio (1545)

"Nobre" aparece na maior parte das vezes como descrição (nobile donna), mas é usado como restritivo para Vetúria, Teoxena, para as matronas que frequentavam o monte Quirinal antes de Júlia Soêmia conspurcá-lo, e como

\footnotetext{
12 "Pelo que não se deve persistentemente recusar à memória as fêmeas desonestas; [...]" (BOCCACCI, 1881, p. 142). Tradução nossa para: "Per la qual cosa non si deve sempre rifiutare la memoria delle disonesti' femmine $[\ldots] "$.

13 "[...] lugares públicos de desonestas fêmeas [...]" (BOCCACCI, 1881, p. 22). Tradução nossa para: "[...] pubblici luoghi di disonesto femmine $[\ldots] "$.

14 "[...] fêmea mortal e desonesta" (BOCCACCI, 1881, p. 20). Tradução nossa para: "[...] femmina mortale e disonesta".
} 
descrição da própria Júlia, a respeito de algo que ela não é (ela se comporta mais como meretriz do que como "mulher nobre"). O gentílico "romana", ao contrário, é majoritariamente restritivo (donna romana), mas para Vetúria e Paulina é usado como descritivo (romana donna).

"Famosa" majoritariamente antecede o nome, ou seja, descreve a mulher. As únicas ocorrências posteriores (restritivas) são em Camiola ${ }^{15}$ e no título do vulgarizamento. Outras mulheres são descritas como famosas, já Camiola é incluída no conjunto das mulheres famosas, mas não recebe essa descrição. Da mesma forma, o título (Delle donne famose) sugere que a obra trata de mulheres que integram o grupo das famosas, mas não que as biografadas sejam "as" famosas mulheres da história. A colocação posterior reitera o que Boccaccio (1545) explica no seu proêmio: ao selecionar certas mulheres para a coletânea, teve consciência de deixar outras de fora.

Se os adjetivos posteriores (restritivos) mostram o pertencimento da mulher a um grupo, é interessante notar que donna vem acompanhado quase que apenas de adjetivos valorados positivamente (gloriosa, nobre, de valor, vencedora, cristã, e as nacionalidades/etnias), e femmina apenas com adjetivos valorados negativamente (liberta/ex-escrava, mortal e desonesta, espantada). Essa separação contribui para reforçar a disforia que o termo femmina assume de maneira geral no texto (como se nota pelas análises feitas até aqui), sentido que pode ser interpretado em seus efeitos culturais sobre uma pretensa ontologia da mulher. Dito em termos semióticos, no livro os papéis temáticos femininos são eufóricos quando se referem à "mulher" e disfóricos quando se referem à "fêmea".

Feitas essas considerações, tratemos da ocorrência majoritária, a dos nomes acompanhados por adjetivos anteriores, aqueles que descrevem uma ou

\footnotetext{
15 "Camiola, mulher viúva famosa pela beleza do corpo e dos costumes, pela generosidade e por laudável honestidade [...]" (BOCCACCI, 1882, p. 371). Tradução nossa para: "Camiola vedova donna famosa di bellezza di corpo, di costume, cortesia e laudabile onestà $[\ldots] "$.
} 
mais mulheres individuadas, em oposição aos restritivos, que caracterizam grupos, tipos de mulheres. Haveria diferenças significativas entre os adjetivos atribuídos a femmina e aqueles atribuídos a donna (quadro 3)?

Quadro 3 - Ocorrência nas biografias de adjetivos qualificativos descritivos que acompanham os substantivos femmina e donna em Delle donne famose.

\begin{tabular}{|l|c|c|}
\hline & femmina & Donna \\
\hline Animosa & Esposa de Ortíago & Irene, Clitemnestra \\
\hline Ousada & Esposa de Ortíago & Atália (duas ocorrências) \\
\hline Desonesta & Lena, Vênus & Júlia Soêmia \\
\hline Gloriosa & Epícaris & Emília, Sulpícia \\
\hline Lasciva & Cleópatra & Popeia Sabina \\
\hline Sagaz & Tômiris & Popeia Sabina \\
\hline Celerada & Cleópatra & Atália \\
\hline
\end{tabular}

Fonte: elaborado por [autor] a partir de Boccacci $(1881,1882)$ e Boccaccio (1545)

Animosa, ousada, desonesta, gloriosa, lasciva, sagaz e celerada ${ }^{16}$ ocorrem com os dois nomes. Não há predominância em termos de número de ocorrências e o conjunto reúne qualidades eufóricas e disfóricas. A regularidade que se nota é o fato de as personagens cujos adjetivos qualificam femmina serem majoritariamente "bárbaras": a esposa de Ortíago é da Galácia (região da atual Turquia); Cleópatra, da África; Tômiris, da Cítia (região entre o atual leste europeu e a Ásia Ocidental); Epícaris era estrangeira (não romana); Vênus é de Chipre; a exceção é Lena, grega mas prostituta. No grupo de adjetivos que qualificam donna, Atália poderia ser "periférica" por ser de Jerusalém, mas o reino fazia parte do império romano, portanto, categoria espacial eufórica. O Egito de Cleópatra também integrava o mesmo império, mas o continente

16 Animosa, ardita, disonesta, gloriosa, lasciva, sagace, scellerata. 
africano é considerado terra de costumes "bárbaros", especialmente no que se refere à luxúria.

Adjetivos que acompanham apenas donna são: amada, antiga, áspera, bela, casta, cruel, cúpida, digna, discreta, famosa, forasteira, forte, gentil, grega, imortal, maravilhosa, nobre, honesta, ótima, pagã, pérfida, comum, prevenida, romana, santíssima, estulta, valente, venerabilíssima ${ }^{17}$. Adjetivos de apenas femmina são: astuta, celestial, desonesta, dissoluta, malvada, riquíssima, esperta, viril $^{18}$ (quadro 4).

Quadro 4 - Ocorrência e categorização de adjetivos qualificativos descritivos que acompanham os substantivos femmina e donna em Delle donne famose.

\begin{tabular}{|l|l|l|}
\hline \multicolumn{1}{|c|}{ femmina } & \multicolumn{1}{c|}{ Donna } \\
\hline Caráter e paixões & $\begin{array}{l}\text { desonesta, dissoluta, } \\
\text { malvada, viril }\end{array}$ & $\begin{array}{l}\text { áspera, casta, cruel, cúpida, digna, discreta, forte, } \\
\text { nobre, honesta, pérfida, santíssima, estulta, valente }\end{array}$ \\
\hline Intelecto & astuta, esperta & Prevenida \\
\hline Dimensão não humana & celestial & Imortal \\
\hline Aspectos físicos & & antiga, bela \\
\hline Reconhecimento externo & & amada, famosa, maravilhosa, ótima, venerabilíssima \\
\hline Estatutos sociais & riquíssima & forasteira, gentil, grega, pagã, comum, romana \\
\hline
\end{tabular}

Fonte: elaborado por [autor] a partir de Boccacci $(1881,1882)$ e Boccaccio (1545)

Em termos de caráter e paixões, donna apresenta tanto qualidades positivas quanto negativas, e femmina apenas negativas; quanto aos recursos do intelecto ocorre algo parecido com o observado na distinção entre as locuções adjetivas: para femmina tem mais a ver com dissimulação, esperteza, enquanto para donna é um uso manifesto da razão. No âmbito da dimensão não humana, inverte-se

\footnotetext{
17 Amata, antica, aspra, bella, casta, crudel, cupida, degna, discreta, famosa, forestiera, forte, gentile, greca, immortale, maravigliosa, nobile, oneste, ottima, pagana, perfida, privata, provveduta, romana, santissima, stolta, valente, venerabilissima.

18 Astuta, celestiale, disonesti, dissoluta, malvagia, ricchissima, scaltrita, virile.
} 
o que se tem observado até então, e o aspecto mais cultural aparece em femmina e o mais natural em donna.

Reconhecimento externo ocorre apenas para donna, e sobre os estatutos sociais, apenas um é para femmina, a riqueza. No livro o adjetivo diz respeito à meretriz Flora, que está num baixíssimo estrato da sociedade romana, mas que enriquece por herança de um marido. Os adjetivos relativos a donna têm a ver com aspectos que definem uma identidade social: nacionalidade, origem (gentile, "nobre") e religião. Na oposição que se manifesta pela diferença da distribuição desses adjetivos, a riqueza é adquirida, enquanto os outros são "de berço". Há que se levar em conta ainda o quanto Boccaccio alerta sobre os perigos do dinheiro e o quanto ele pode corromper o homem e a sociedade. Nesse contexto, o qualificativo, que aparece para femmina, é disfórico.

\section{Femmina e donna nas biografias}

Falemos, então, da ocorrência dos termos nas biografias. Para isso, consideremos a categorização proposta pela medievalista Virginia Brown (2003). Essa divisão leva em conta que Boccaccio organizou as biografias em ordem mais ou menos cronológica, e que uma primeira intenção seria tratar apenas de personagens da Antiguidade, especialmente greco-romana, conjunção espaçotemporal que ele considerava modelar para a organização e funcionamento das cidades e da vida social. Os quatro últimos capítulos relatam as vidas de mulheres medievais, e são vistos por alguns estudos (ARGURIO; ROVERE, 2017) como um acréscimo pensado posteriormente, em uma segunda fase redacional, com vistas à conquista de um lugar na corte de Nápoles.

As duas primeiras biografias, de Eva e Semíramis (rainha da Babilônia), não são categorizadas por Brown, mas ambas podem ser entendidas como mulheres "fundadoras" da humanidade: Eva no sentido natural, a "mãe" de 
todos os humanos, e Semíramis no sentido cultural, diante do que representou a Babilônia em termos de civilização. O grupo seguinte, já na classificação de Brown, é composto por seis deusas pagãs (capítulos III a VIII — Opis, Juno, Ceres, Minerva, Vênus e Ísis); depois, 32 capítulos (IX a XL) com as vidas de figuras mitológicas gregas e romanas de estatuto heróico ou semidivino (por exemplo: Europa, Medusa, algumas rainhas das amazonas, Jocasta, a cartaginesa Dido); apesar de não tratar de mulheres célebres do cristianismo, Boccaccio incluiu três biografias de mulheres citadas na Bíblia: Nicaula (a rainha de Sabá, capítulo XLI), Atália (rainha de Jerusalém, capítulo XLXIX) e Mariane (esposa de Herodes Antípatre, capítulo LXXXV); o último grupo, com 61 biografias, inclui personagens "históricas" (no sentido de que as fontes de Boccaccio para elas são entendidas como históricas, a exemplo de Tácito), especialmente da república e do império romano e incluindo as quatro figuras da pósAntiguidade.

Observando a ocorrência dos termos em cada grupo (quadro 5), nota-se que quanto mais "primitivas" as mulheres, maior é a proporção do uso de femmina. No caso das mulheres "históricas", mais recentes no tempo e de existência social documentada pelos protohistoriadores da Antiguidade, aumenta o índice de uso de donna.

Quadro 5 - Ocorrência dos termos femmina e donna nas categorias de biografias de Delle donne famose.

\begin{tabular}{|l|c|c|c|c|c|}
\hline \multicolumn{1}{|c|}{ Categoria } & Total & donna & \% & femmina & \% \\
\hline antigas & 18 & 10 & $56 \%$ & 8 & $44 \%$ \\
\hline deusas pagãs & 15 & 10 & $67 \%$ & 5 & $33 \%$ \\
\hline mitologia greco-romana & 76 & 55 & $72 \%$ & 21 & $28 \%$ \\
\hline bíblicas & 13 & 9 & $69 \%$ & 4 & $31 \%$ \\
\hline históricas & 298 & 230 & $77 \%$ & 68 & $23 \%$ \\
\hline Total & $\mathbf{4 2 0}$ & $\mathbf{3 1 4}$ & $75 \%$ & $\mathbf{1 0 6}$ & $25 \%$ \\
\hline
\end{tabular}


Fonte: elaborado por [autor] a partir de Boccacci $(1881,1882)$ e Boccaccio (1545) e com base nas categorias de Brown (2003)

Analisemos a seguir esse resultado, junto àqueles das seções anteriores, para consolidar as posições axiológicas assumidas pelos termos em cada um dos três aspectos selecionados para observação.

\section{Discussão dos resultados}

Para facilitar a interpretação das informações obtidas em cada um dos recortes realizados, organizemo-las em um resumo esquemático:

a. ocorrência geral: no livro como um todo, a ocorrência de donna $(75 \%)$ é maior do que a de femmina (25\%);

b. locuções adjetivas: os termos podem assumir a função de substantivo ou de adjetivo (locuções adjetivas di femmina ou di donna). Considerando as ocorrências de cada termo, femmina forma mais locuções adjetivas (32\%) do que donna (16\%);

c. substantivos adjetivados pelas locuções: de forma geral, as locuções formadas com donna qualificam substantivos mais eufóricos do que aquelas formadas com femmina; substantivos relacionados ao caráter são todos disfóricos para femmina, e todos eufóricos para donna. Aqueles relacionados à ação do intelecto manifestam uma inteligência cultivada para donna e intuitiva para femmina; aspectos culturais como roupas, normas, leis e organização coletiva são mais caracterizados como di donna do que como di femmina; locuções que ocorrem formadas tanto por um quanto por outro termo aparecem relacionadas a contextos ou biografias disfóricas quando di femmina e eufóricas quando di donna;

d. outras acepções dos substantivos: donna di popolo é plebeia em abordagem eufórica, diferente da plebeia de femmina di popolo; femmina e donna determinadas com pronomes possessivos assumem sentidos distintos: 
empregadas, servas, concubinas no primeiro; esposas, filhas, parentes no segundo;

e. adjetivo qualificativo: ocorre mais para donna (44\%) do que femmina $(30 \%)$

f. adjetivos posteriores/restritivos: mais eufóricos quando ocorrem em donna do que quando ocorrem em femmina. Na medida em que categorizam tipos de mulher (papéis temáticos), a foria da predicação associa tipos negativos a femmina e positivos e de pertencimento/papel social (gentílicos) a donna;

g. adjetivos anteriores/descritivos: adjetivos (eufóricos ou disfóricos) que ocorrem junto aos dois nomes aparecem nas mulheres "bárbaras" predicando femmina e nas "civilizadas" predicando donna; adjetivos que descrevem donna são em geral mais eufóricos que aqueles que descrevem femmina; qualidades que dizem respeito a estatuto social e reconhecimento externo predicam apenas donna;

h. ocorrência dos termos nas biografias: quanto mais "primitivo" o grupo, maior a ocorrência de femmina para designar a mulher e as mulheres.

Assim como o enunciado de Boccaccio propõe uma dicotomia pedagógica articulada em virtudes e pecados a serem respectivamente seguidos e evitados pelas mulheres, a análise dessa obra, concentrada nas suas ocorrências de femmina e donna, faz emergir outras axiologias. Estas dizem respeito à oposição bárbaro x civilizado, primitivo x desenvolvido, intuição x intelecto, servidão x cidadania, natureza x cultura. Exceto por alguns desvios, elas podem ser sobrepostas e respectivamente homologadas àquela constituída pelos termos femmina $\mathrm{x}$ donna, em cuja axiologia o primeiro termo assume foria negativa e $\mathrm{o}$ segundo positiva.

No entanto, a homologação dessas categorias não recobre necessariamente aquela da pedagogia boccacciana; apesar de se observar que alguns adjetivos relacionados à moral, quando disfóricos, aparecem mais 
relacionados a femmina, as outras dicotomias suplantam essa. Essa constatação incrementa as abordagens que apontam contradições do livro e questionam seu caráter eminentemente moralizante.

O ponto deste artigo, porém, é outro: verificar, por meio da análise, se, atendendo à volição do texto para uma diferenciação na designação da pessoa do sexo feminino, haveria fundamento para se usar o par "fêmea" e "mulher" como tradução de femmina e donna. A questão se coloca porque os sentidos de "fêmea" no português têm uma carga disfórica maior do que aquela de femmina no italiano do século XIV, o que poderia interferir mais do que o desejado nos efeitos de sentido do texto.

Esses sentidos do PB não são negativos quando o termo designa o reino animal. A disforia acontece quando ele é usado para se referir ao ser humano. As acepções depreciativas se fundam na projeção de aspectos considerados animalizados. Esses aspectos são a autonomia e liberalidade sexual (fêmea como sinônimo de prostituta), o assentimento a relações afetivo-sexuais não chanceladas institucionalmente (fêmea como sinônimo de amante), a forte atratividade sexual. Chamar uma mulher de fêmea é evocar aspectos de uma sexualidade feminina vista geralmente, nos lembra Rebecca Solnit (2016, p. 392, grifos nossos), como "[...] caótica, ameaçadora e subversiva, uma espécie de natureza selvagem a ser subjugada pela cultura masculina".

Portanto, na axiologia dos usos desses termos,"natural" é disfórico, "cultural" é eufórico. O simulacro de "mulher" em oposição ao de "fêmea" é construído culturalmente sobre valores de contenção sexual, negação da agressividade, adesão às normas institucionais e adequação aos papéis sociais. O disfórico em Delle donne famose está relacionado à homologação entre o papel temático femmina e o valor "natureza", disfórico na axiologia que estabelece com a "cultura" e com o papel temático donna. Reitera-se a distinção que começava 
a se estabelecer no século XIV e que se observara em Dante, como mencionado por Bonfante (1958) e Delcorno (1970).

Tendo isso em vista, o que há de disfórico no termo "fêmea" no PB conjuga sentidos observados nos usos do femmina no livro, tornando-o pertinente para compor, com "mulher", a distinção estabelecida pela enunciação do texto italiano. Na tradução brasileira, "fêmea" ajudará a compor o sentido de disforia das mulheres ou das qualidades femininas primitivas, bárbaras, de estatuto social inferior, de agrupamento amorfo e não politicamente organizado, de costumes dissolutos e estrangeiros, de caráter menos nobre e raciocínio mais intuitivo.

Antes de concluir, uma observação: ocorre no livro uma diferenciação da denominação das pessoas do sexo masculino, chamadas de nomo e de maschio, que poderiam corresponder ao "homem" e "macho" do português. A relação entre eles, no entanto, é bem diferente daquela entre os termos do par feminino. Uomo, que designa tanto uma pessoa, um grupo e a humanidade em geral, ocorre em 93\% dos casos. O livro reserva ao homem mais pertencimento à cultura, e à mulher mais à natureza.

\section{Considerações finais}

A discussão apresentada neste artigo partiu da questão sobre como presentificar, com o português brasileiro, os efeitos de sentido produzidos pela axiologia femmina $\mathrm{x}$ donna, do italiano do século XIV, na tradução do Delle donne famose de Giovanni Boccaccio. Essa diferenciação parece ser necessária pois sua ocorrência manifesta uma volição do sujeito da enunciação.

Sendo necessária a diferenciação, para que serviria? A análise das ocorrências desautomatiza sentidos previamente dados pelos dicionários e mostra, nas regularidades e exceções, a emersão de outros pares axiológicos 
relacionados às concepções de mulher e à valoração de categorias fundamentais de organização humana, como estatuto social, alteridade, grau civilizatório.

Femmina e donna, ao serem sobrepostos a essas axiologias, compõem uma homologação que adensa a isotopia temática e figurativa de cada um deles e complexifica o contrato pedagógico boccacciano, que só na aparência é fundado exclusivamente na maniqueísta oposição entre pecado e virtude.

Ainda que, pelos dicionários, os sentidos de femmina e de "fêmea" não se sobreponham totalmente e convoquem graus distintos de valoração negativa, o foco no caráter natural em oposição ao cultural das acepções disfóricas autoriza que o "fêmea" cumpra, no português, as função de significação assumida pelo femmina no italiano.

\section{Referências}

ARGURIO, Silvia; ROVERE, Valentina. Boccaccio alla corte di Napoli: le redazioni del De mulieribus claris. In: AGHELU, Marialaura et al. (a cura di). Studi (e testi) italiani, n. 40, p. 13-25, 2017.

BOCCACCI, Giovanni. Delle donne famose. 3. ed. Tradução Donato degli Albanzani di Casentino. Edição, proêmio e notas de Giacomo Manzoni. Bologna: Gaetano Romagnoli, 1881. v. 1.

BOCCACCI, Giovanni. Delle donne famose. 3. ed. Tradução Donato degli Albanzani di Casentino. Edição, proêmio e notas de Giacomo Manzoni. Bologna: Gaetano Romagnoli, 1882. v. 2.

BOCCACCIO, Giovanni. De claris mulieribus. Volgarizzamento di Maestro Donato da Casentino. Cura e studio di D. Luigi Tosti. Napoli: Tipografia dello stabilimento dell'Ateneo, 1836.

BOCCACCIO, Giovanni. Delle donne illustri. Con una additione fatta dal medesimo [...] Tradução e acréscimos Giuseppe Betussi. Vinegia: 1545.

BROWN, Virginia. Introduction, notes, index. In: BOCCACCIO, Giovanni. Famous women. Tradução, introdução e notas Virginia Brown. Cambridge, London: Harvard University Press, 2003. p. xi-xxi; 235-256; 263-282. 
DELCORNO, Carlo. Donna. Enciclopedia Dantesca, 1970. Disponível em: https://www.treccani.it/enciclopedia/donna_\%28EnciclopediaDantesca\%29/. Acesso em: 19 nov. 2020.

JULIANI, Talita Janine. Sobre as Mulheres Famosas (1361-1362) de Boccaccio tradução parcial, estudo introdutório e notas. 2011. 286 p. Dissertação (Mestrado em Linguística) - Instituto de Estudos da Linguagem, Universidade Estadual de Campinas, Campinas, 2011 Disponível em: http://www.repositorio.unicamp.br/handle/REPOSIP/270798. Acesso em: 17 jan. 2020.

KIRKHAM, Victoria. A Cannon of Women in Dante's Commedia. Annali d'italianistica, n. 7, p. 16-41, 1989. Edição especial "Women's voices in Italian LIterature" organizada por Rebecca West e Dino Cervigni.

PANEBIANCO, B.; PISONI, C.; REGGIANI, L. Grammatica italiana: la lingua italiana in pratica. Bologna: Zanichelli Editore, 2017.

SOLNIT, Rebecca. A bistória do caminhar. Tradução Maria do Carmo Zanini. São Paulo: Martins Fontes, 2016.

TOMMASI, Alessia. Il volgarizzamento del "De mulieribus claris" di Donato Albanzani. Censimento dei manoscritti e proposta per una nuova datazione dell'opera. In: ZAMPONI, Stefano (org.). Intorno a Boccaccio / Boccaccio e dintorni, 2018. Atti del Seminario internazionale di studi. Firenze: Firenze University Press, 2020. p. 129-168. Disponível em: https://doi.org/10.36253/978-886453-997-3. Acesso em: 6 ago. 2020. 